\title{
Mesenteric Panniculitis (MP): A Frequent Coincidental CT Finding of Debatable Clinical Significance
}

\section{Panniculitis mesenterialis (PM): ein häufiger CT-Zufallsbefund mit umstrittener klinischer Relevanz}

Authors

Özlem Gögebakan ${ }^{1}$, Martin A. Osterhoff ${ }^{2}$, Thomas Albrecht ${ }^{1}$

Affiliations

1 Department for Radiology and Interventional Therapy, Vivantes Klinikum Neukölln, Berlin, Germany

2 CBF, Department for Endocrinology, Diabetes and Nutrition, Charité - Univesrsitätsmedizin Berlin, Germany

Key words

abdomen, $\mathrm{CT}$, mesentery, inflammation, lymphoma, paraneoplastic phenomenon

received 22.09.2017

accepted 14.05.2018

\author{
Bibliography \\ DOI https://doi.org/10.1055/a-0633-3558 \\ Published online: 6.9.2018 \\ Fortschr Röntgenstr 2018; 190: 1044-1052 \\ (c) Georg Thieme Verlag KG, Stuttgart · New York \\ ISSN 1438-9029
}

Correspondence

Frau Dr. Özlem Gögebakan

Institut für klinische und interventionelle Radiologie, Vivantes Klinikum Neukölln, Rudower Str. 48, 12351 Berlin, Germany

Tel.: ++49/30/130142071

Fax: $++49 / 30 / 130143271$

oezlem.goegebakan@vivantes.de

\section{ZUSAMMENFASSUNG}

Hintergrund Bei einer Panniculitis mesenterialis (PM) handelt es sich um eine unspezifische, chronische Veränderung des mesenterialen Fettgewebes unklarer Ätiologie. Sie ist bevorzugt bei Männern und häufig im mittleren bis höheren Erwachsenenalter anzutreffen. Die PM wird in der Regel als Zufallsbefund im Rahmen einer abdominellen CT-Untersuchung festgestellt.

Methoden Es wurde eine umfassende Literaturrecherche in PubMed durchgeführt, bei der Fallberichte und Kohortenstudien einer systematischen Betrachtung unterzogen wurden. Schlüsselwörter waren (und/oder) "Mesenteric Panniculitis“, „Panniculitis mesenterialis“, „mesenteric lymph nodes“, „CT“, „imaging“, „sclerosing mesenteritis“, „case report“, „therapy“.
Ergebnisse und Schlussfolgerung Die PM kommt relativ häufig vor, bleibt jedoch oft im CT-Befund unerwähnt. Somit ist von einer größeren Prävalenz als den berichteten 0,6 bis $2,4 \%$ auszugehen. Die wichtigste, mitunter schwer abzugrenzende Differentialdiagnose, ist das maligne Lymphom. In der Mehrzahl der Fälle bleibt die PM asymptomatisch, selten ist sie Ursache für ein unspezifisches klinisches Erscheinungsbild u. a. mit Bauchschmerzen, Fieber, Erbrechen oder Übelkeit. In äußerst seltenen Fällen besteht eine Therapieindikation; in der Literatur wird hauptsächlich der Einsatz von Glukokortikoiden und Tamoxifen beschrieben. In der Vergangenheit wurde häufig die These vertreten, eine PM sei mit verschiedenen Erkrankungen assoziiert bzw. ein paraneoplastisches Phänomen. Vier kürzlich publizierte Studien mit Fall-Kontroll-Design kommen jedoch zu dem Schluss, dass es sich bei der PM um eine unspezifische, benigne Veränderung handelt. Zwei weitere Studien weisen wiederum auf eine mögliche Assoziation mit malignen Lymphomen hin. Der klinische Stellenwert der PM bleibt somit weiterhin Gegenstand wissenschaftlicher Diskussionen.

\section{Kernaussagen:}

- Die Panniculitis mesenterialis (PM) ist eine unspezifische, chronische Entzündung des mesenterialen Fettgewebes mit charakteristischen Zeichen im CT.

- Die PM stellt häufig einen CT-Zufallsbefund dar

- Die wichtigste Differentialdiagnose ist das maligne Lymphom

- Eine Assoziation mit anderen und insbesondere malignen Erkrankungen wird diskutiert, lässt sich jedoch nicht eindeutig nachweisen

- Die PM wird äußerst selten klinisch symptomatisch, wenn dann mit z. B. Fieber, Übelkeit, Erbrechen, Bauchschmerzen

\section{ABSTRACT}

Background Mesenteric panniculitis (MP) is histologically characterized by chronic nonspecific inflammation of the adipose tissue of the intestinal mesentery with unclear etiology. MP occurs predominantly in men, mostly in mid to late adulthood. MP is typically found as an incidental diagnosis on abdominal CT. 
Methods A comprehensive review of the literature including case reports and cohort studies was performed. Therefore, a global search in PubMed was carried out. Search terms were (and/or) "mesenteric panniculitis”, "panniculitis mesenterialis”, “mesenteric lymph nodes”, “CT”, “imaging”, "sclerosing mesenteritis", "case report", "therapy".

Results and Conclusion MP is a relatively common CT finding. The true prevalence seems to be higher than the reported $0.6 \%$ to $2.4 \%$ due to underreporting. The most important differential diagnosis is malignant lymphoma, which may be difficult to distinguish from MP. The majority of patients with MP are clinically asymptomatic and do not require therapy. In rare symptomatic cases, non-specific symptoms like abdominal pain, fever, nausea or vomiting occur. For therapy, glucocorticoids and tamoxifen have been suggested. Several studies suggested that MP is associated with other diseases and might be a paraneoplastic phenomenon, but four recently published case-control studies suggest that MP is an independent non-specific benign age-related phenomenon. However, two further studies show a possible association of MP with malignant lymphoma. The clinical relevance of MP remains the subject of scientific debate.

\section{Key Points:}

- Mesenteric panniculitis (MP) is a non-specific, chronic inflammation of the mesenteric adipose tissue with characteristic CT signs

- MP is a relatively common incidental finding on abdominal CT

- Malignant lymphoma is the main differential diagnosis

- An association of MP with other diseases including malignancy has been discussed but cannot be confirmed unequivocally

- MP is rarely symptomatic with fever, nausea, vomiting, abdominal pain, or diarrhea

\section{Citation Format}

- Gögebakan Ö, Osterhoff MA, Albrecht T. Mesenteric Panniculitis (MP): A Frequent Coincidental CT Finding of Debatable Clinical Significance. Fortschr Röntgenstr 2018; 190: 1044-1052

\section{Definition}

Mesenteric panniculitis (MP) is a nonspecific inflammatory condition of the mesenteric adipose tissue first described during abdominal surgery by Jura as early as 1924 [1]. The process usually involves the mesentery of the small bowel, especially at its root, and only rarely involves the mesocolon [2, 3]. On rare occasions, MP may also affect the peripancreatic region, omentum, retroperitoneum, or pelvis [4]. The term "panniculitis" deriving from lat. panniculus = "lobule" (diminutive of pannus = "lobe") describes a local sheet or layer of inflammatory adipose tissue without explaining the etiology. It was first used for inflammation of subcutaneous adipose tissue like that occurring several weeks after severe cold exposure (coldness panniculitis also known as panniculitis type Rothmann-Makai or lipogranulomatosis subcutanea).

MP is sometimes also referred to as sclerosing mesenteritis [5], mesenteric lipodystrophy [6] or misty mesentery [7]. While these terms have to some extent been confounded in the past, the term sclerosing mesenteritis was proposed as an umbrella term by Emory et al. [5]. Inflammatory disorders of the mesenteric root today are usually divided into two distinct pathological subgroups, which can be differentiated by histological criteria, into MP and retractile sclerosing mesenteritis. In MP, fat necrosis predominates, while in retractile sclerosing mesenteritis, which is now seen as a different disease, fibrosis and retraction are the prevailing features, often leading to small bowel obstruction/ileus in affected patients $[8,9]$.

\section{Epidemiology}

Initially, Kuhrmeier identified the phenomenon which later was called MP as a mesenteric lipodystrophy with typical macroscopic and histopathological changes of the mesenteric adipose tissue in
9 of 712 autopsies (1.26\%) [10]. Today, the diagnosis of MP is typically made on abdominal cross-sectional imaging, mainly $C T$, as an incidental finding. In the CT literature, the reported prevalence of MP is around $0.6-2.4 \%[6,11,12]$. While some authors report higher prevalence of $2.4-7.8 \%$ [13-16], Wilkes et al. [17] found a prevalence as low as $0.16 \%$. The diverging values in these studies may be due to over- or underreporting by radiologists or to selection bias in certain centers. Since radiologists may not always be familiar with MP and its specific imaging findings, underreporting appears likely, so that the true prevalence of MP on imaging can be expected to be higher than described in the literature. A further problem might be that the search for MP in retrospective studies is often carried out by a free text search not always revealing cases in which MP is described by an unconventional term. Many studies also lack the exact description of the search terms making it difficult to evaluate the integrity of the search.

Most of the studies reported a higher prevalence in men than in women $(2: 1-3: 1)[3,5,11,13,18-20]$. The disorder usually occurs in mid or late adulthood $[6,21]$ with a mean age above 50 years $[11,12,15,21-26]$.

\section{Etiopathology and association with other disease}

The cause of MP remains obscure and is subject to debate. MP is characterized histologically by chronic nonspecific inflammation of the adipose tissue of the intestinal mesentery. Biopsy samples of MP patients show infiltration of the mesenteric fat with a large number of lipid-laden macrophages scattered among fat cells or fully replacing them, probably representing a reaction to fat necrosis, and dispersed lymphocytic aggregates and lymphoid 
follicles. Moreover, a variable degree of fibrosis is noted. Acute inflammatory exudates and vasculitis are absent [11].

A number of different co-morbidities occurring with MP have been described in the literature, mainly in case reports or small series without control groups. From these, it is very difficult to judge if MP was the trigger of the reported comorbidities or their consequence and whether there was any causal association.

Trauma (including recent surgery), infection, ischemia of the mesentery and idiopathic inflammatory disorders such as retroperitoneal fibrosis, sclerosing cholangitis, Riedel thyroiditis and orbital pseudotumor have been implicated in this context. Autoimmunity (some authors suggest an IgG4-related disease [27 29]) in the context of established collagen vascular disease as well as unknown causes have been proposed as possible mechanisms, albeit rather for the manifestation as sclerosing mesenteritis than for MP $[30,31]$. An association with abdominal surgery and diverticulitis has also been reported [3]. Due to the lack of control groups in all these publications, it remains unclear if any of the aforementioned associations were significant or merely coincidental.

\section{MP and its association with malignant and other diseases}

As mentioned above, several studies have reported an association of MP with malignancy, i. e., lymphocytic leukemia [32, 33], lymphoma and myeloma [34, 35], malignant neoplasms [6], adenocarcinoma of the endometrium [36], carcinoma of the stomach and pancreas [35], tuberculous lymphadenitis [37]. Kipfer et al. found malignancies in $30 \%$ of MP patients [6], a fact which was later confirmed by Daskalogiannaki et al. with an even higher rate of $69.3 \%$ [11]. Canyigit et al. reported neoplasia in $17.6 \%$ of patients with MP [13] and Wilkes et al. in $38 \%$ of their MP patients [17]. In a recent Australian study by Cross et al. including a total of 259 MP patients, only $30 \%$ had neoplasia [23]. Overall, lymphoma was the malignancy most frequently associated with MP. According to a systematic review of 13 CT studies, the average rate of malignancy in MP patients was $38 \%$ with a range from $8-89 \%$ in individual studies; $25 \%$ of these malignancies were lymphoma [25]. A recent study also reported an increased prevalence of MP in patients with lymphoma [26].

Most of the authors of the aforementioned studies speculate that MP may be a paraneoplastic phenomenon. With respect to the aim of investigating the association of malignancies with MP, however, all these studies suffer from the crucial limitation of lacking a control group or a design to investigate the prevalence of malignancy in non-MP patients in the same CT cohort.

More recently, several studies with control groups were published, further elucidating whether any of the associated pathologies were more common in patients with MP than in the control groups. Consequently, these studies were designed to validate possible causal interactions between MP and the mentioned comorbidities, especially paraneoplastic phenomena $[12,14,15,24-26]$. In the first case-control study by Gögebakan et al. with more than 13000 patients undergoing abdominal CT, 77 patients with MP and 152 control patients matched for year of $\mathrm{CT}$ examination, $\mathrm{CT}$ protocol, sex, age and abdominal diameter at umbilical level were analyzed [12]. In this study, no significant association with any of the abovementioned entities could be confirmed. With regard to malignancy, the rate was $50.6 \%$ in the MP group and $61.2 \%$ in controls, i. e., even slightly, albeit not significantly, lower in the MP group. The majority of patients with a severe or very severe grade of MP showed no evidence of malignancy at all. In a subgroup of 39 patients who underwent followup CT, the evolvement of malignancy and MP grade were analyzed, with no association found. Furthermore, there was no significant difference in the rate of frequent concomitant diseases such as hypertension, diabetes or previous surgery between the two groups [12].

A second case-control study using a similar design by van Putte-Katier followed two years after the first case-control study. The authors found a significant association between malignancies and MP in a post-hoc matched pair analysis; the rate of malignancy was $48.9 \%$ in the MP group versus $46.2 \%$ in the control group $(p<0.05)$ [14]. There was a statistically significant $(p<0.05)$ higher prevalence of subjects with prostatic carcinoma in the MP group $(34.8 \%$ ) compared to control patients (26.3\%). During follow-up the number of malignancies increased more strongly in the MP group $(p<0.05)$ [14]. However, one statistical flaw in the described analysis was the use of a McNemar test, which is only correct for paired samples in terms of evaluating the same subjects in a before-after manner or siblings, but not for different subjects in a matched pair analysis when the number of cases is too low. Consequently, the significance of the association between prostatic carcinoma and MP remains questionable. Unfortunately, concomitant diseases such as inflammatory bowel disease, abdominal surgery, cardiovascular disease, hypertension and diabetes were cited only for subjects with MP but not for controls, thus preventing conclusions on the association of such diseases with MP [14].

A third case-control study published by Protin-Catteau et al. [15] used a similar design as the first case-control studies. In this study with $96 \mathrm{MP}$ patients and 192 controls, the prevalence of co-morbidities as well as malignancies was compared between both groups. The fraction of patients with malignancies did not differ significantly in patients with MP (60.4\%) and control patients (59.4\%) except for lymphoma and melanoma. Likewise, during a 5-year follow-up, no higher prevalence of neoplasia was found in the MP group. Furthermore, an association between MP and other comorbidities, such as hypertension, diabetes, diverticulitis, etc., could not be verified by Protin-Catteau and colleagues [15].

A fourth case-control study by Scheer at al. also claimed to demonstrate an association of malignancies with MP [26]. The authors compared patients with and without MP from an overall CT population of 5595 patients. The incidence of malignancies was $74.8 \%$ in patients with MP compared to $35.2 \%$ in the overall population. The highest prevalence of MP was found in patients with Non-Hodgkin Lymphoma (22.6\%). One limitation of this study is that the control group was not matched with MP patients, so that e. g. patients in the MP group were significantly older than in the overall population, which in itself may account for a higher incidence of malignancy [26]. Furthermore, it is often difficult to definitely distinguish lymphoma from enlarged lymph nodes in 
the context of MP. Valid markers for MP would be the "fat ring" sign and a pseudocapsule. The authors do not clearly specify which typical radiological criteria of MP accompany the confirmed cases of lymphoma in their study. For example, there is no information on whether the twelve subjects lacking the pseudocapsule sign are the same that also lacked a fat-ring sign. Since "fat-ring" sign and pseudocapsule might be the most suitable markers to diagnose MP $[8,11,38]$ in the presence of non-Hodgkin lymphoma, this would have been interesting information. As a result, it remains unclear whether a fraction of the confirmed lymphoma patients might have been spuriously assigned to the MP group [26].

Moreover, the mentioned differences may be due to a slight bias resulting from different populations visiting the respective hospitals or from different matching modalities.

However, in three case-control studies $[12,14,15]$ a prevalence for malignancies in the MP group as well as in the control group of approximately $50 \%$ is reported or - vice versa - in one case-control study the prevalence of MP in the lymphoma and the control group are similar [39]. Furthermore, a recent cohort study by Buchwald et al. [24] confirms the follow-up data of Gögebakan et al. [12] and Protin-Catteau et al. [15]. In their cohort of 173 patients with verified MP, Buchwald et al. evaluated in a 13-year follow-up (2003-2015) whether patients with or without malignancies differed in terms of the rate of remission or aggravation of MP, and whether the treatment of malignancies influenced the severity of MP. The authors did not find statistical evidence of any association between the course of MP and that of the concomitant malignant disease in any scenario [24].

A systematic review by Halligan et al. [25] of past studies addressing the question of whether or not MP might be a paraneoplastic phenomenon comes to the qualitative conclusion (heterogeneity of the study designs prevented a meta-analysis) that an association between MP and malignancy cannot be determined.

Recently, a case-control study to analyze a possible association between MP and lymphoma was published by Khasminsky et al. [39]. The authors evaluated 166 subjects with Non-Hodgkin-Lymphoma (NHL) and 332 control subjects matched for gender and age by combined CT/PET examinations. In the NHL group the prevalence of MP was the same as in the control group leading to the conclusion that MP and lymphoma are not associated [39].

In a retrospective study without a control group, Ehrenpreis et al. found 359 patients with MP-like findings out of a total of 147794 subjects with CT scans [40]. Of these 359 patients with MP-like findings, 81 patients had a known cancer history and 19 a newly diagnosed malignancy. The greatest fraction again was patients with lymphoma (36), 27 with a known history and 9 newly diagnosed. Based on the fact that the initial likelihood of an existing malignancy was only $5 \%$ and a new diagnosis of cancer was only found in $1.4 \%$ of subjects with MP, the authors concluded that a new diagnosis of malignancy in patients with MP-like findings is a rare event. Additionally, the authors concluded from the fact that MP-like signs usually remain stable in patients with known malignancies that MP might be a paraneoplastic phenomenon [40].
- Table 1 MP signs according to Coulier [16]. At least 3 of the 5 signs are required to diagnose MP.

- Tab. 1 Zeichen für PM nach Coulier [16]. Mindestens 3 der 5 möglichen Zeichen sind erforderlich, um eine PM zu diagnostizieren.

\begin{tabular}{|l|l|}
\hline \multicolumn{1}{|l|}{ sign } \\
\hline 1 & $\begin{array}{l}\text { a well-defined fatty mass at the root of the small bowel } \\
\text { mesentery displacing neighboring structures }\end{array}$ \\
\hline 2 & $\begin{array}{l}\text { sign } 1 \text { with a higher attenuation than that of retroperitoneal } \\
\text { or subcutaneous fat tissue }\end{array}$ \\
\hline 3 & \begin{tabular}{l} 
lymph nodes within this well-defined fatty mass \\
\hline 4
\end{tabular} \\
\hline 5 & $\begin{array}{l}\text { a hypodense halo surrounding blood vessels and nodes } \\
\text { with the lymph nodes within }\end{array}$ \\
\hline
\end{tabular}

- Table 2 Scoring system for signs and severity of MP according to Coulier [16]. Each sign is scored according to its grade and all scores are totaled to calculate the grade of MP.

- Tab.2 Punktesystem für Zeichen und Schweregrad einer PM nach Coulier [16]. Jedes sichtbare Zeichen wird zunächst gewichtet und alle daraus resultierenden Punkte summiert, um letztendlich den Schweregrad der PM zu ermitteln.

\begin{tabular}{|l|l|l|l|}
\hline \multicolumn{2}{|c|}{ scoring of MP signs } & \multicolumn{2}{|l|}{ severity of MP } \\
\hline score & occurrence/grade & $\begin{array}{l}\text { sum of scores of } \\
\text { MP signs }\end{array}$ & grade \\
\hline 0 & absent & & \\
\hline 1 & discrete & $3-4$ & minimal \\
\hline 2 & moderate & $5-9$ & moderate \\
\hline 3 & marked & $10-15$ & marked \\
\hline
\end{tabular}

However, in view of recent case-control studies reporting similar numbers of patients with malignancies but without symptoms of MP, this conclusion appears to be questionable [12, 15, 24, 25].

In conclusion, all of these studies do not provide convincing statistical evidence of an association of concomitant diseases including malignancies with MP [12, 14, 15, 24 - 26, 39, 40]. All discussed studies are summarized in $>$ Table 3.

\section{Clinical Symptoms}

There are no specific clinical symptoms of MP. Nevertheless, patients may present with palpable abdominal mass and symptoms, including abdominal pain, nausea, diarrhea, pyrexia, weight loss and bowel disturbance of variable duration [5, 22, 41 - 43], especially in rare cases where retraction of the mesentery leads to bowel obstruction or, less commonly, to mesenteric ischemia $[6,28,44-46]$. In most cases of MP, however, clinical symptoms 


\begin{tabular}{|c|c|c|c|c|c|c|c|c|}
\hline & 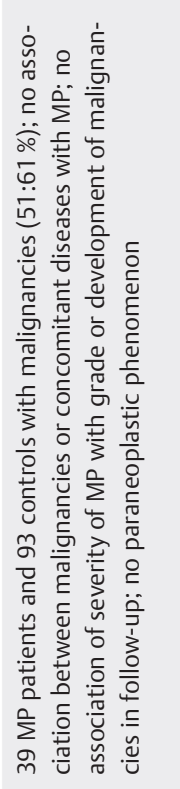 & 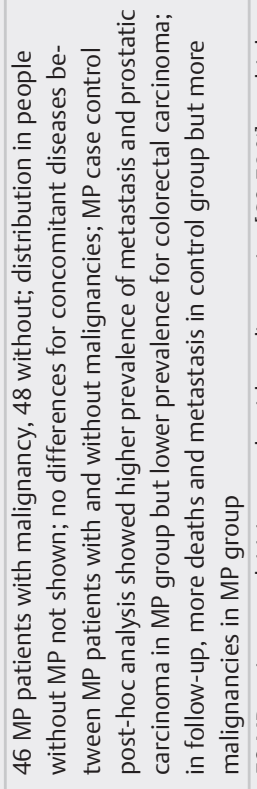 & 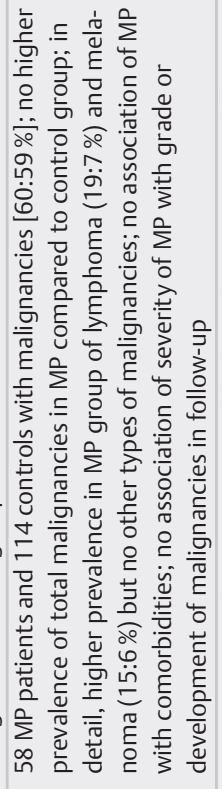 & 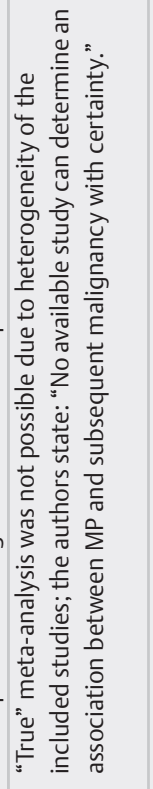 & 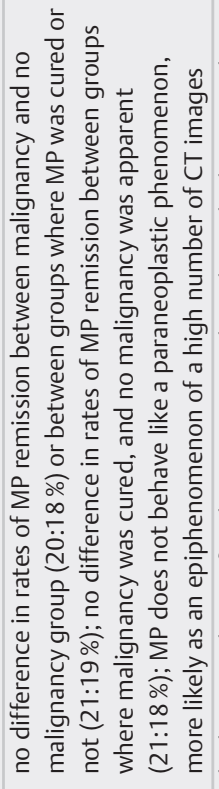 & 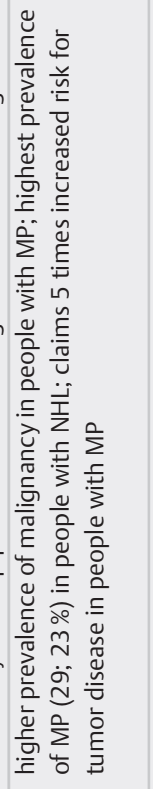 & 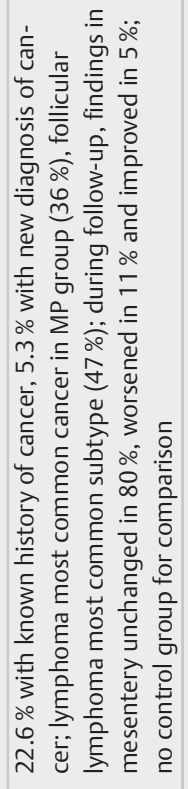 & 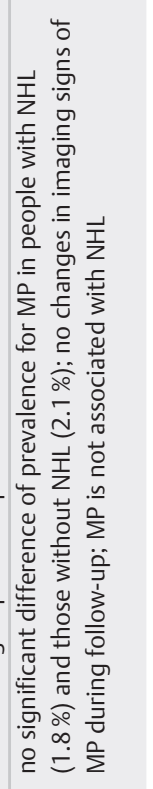 \\
\hline 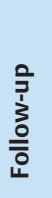 & 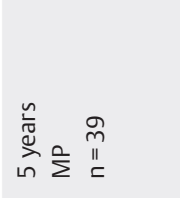 & 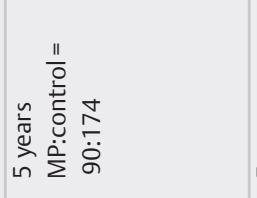 & 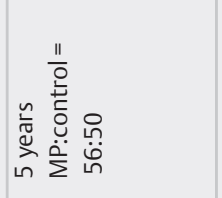 & $\Sigma$ & 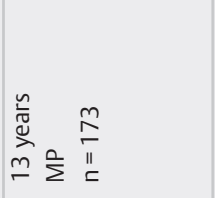 & $\stackrel{\circ}{ }$ & 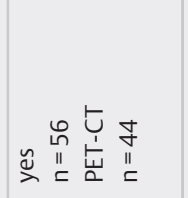 & 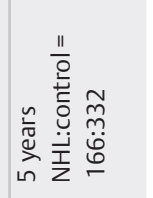 \\
\hline 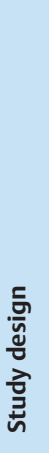 & 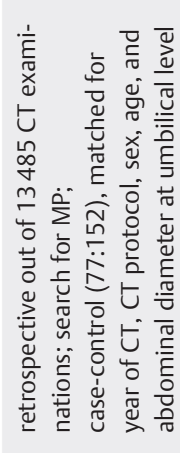 & 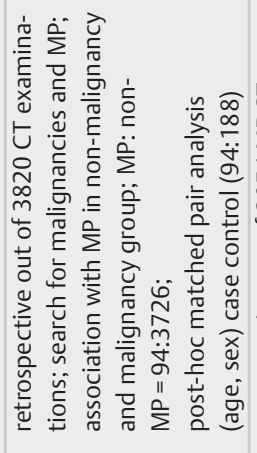 & 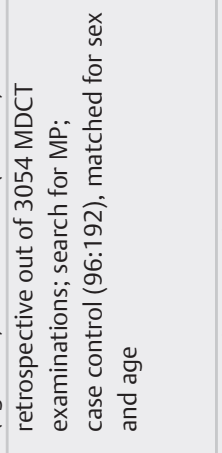 & 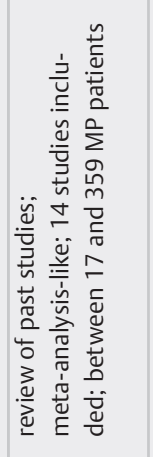 & 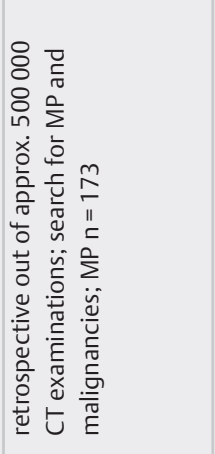 & 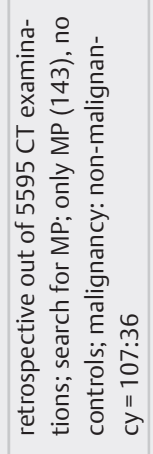 & 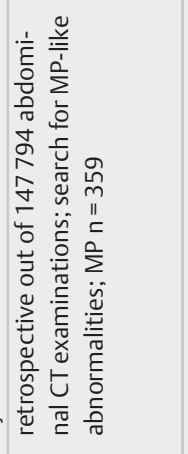 & 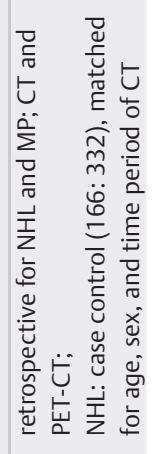 \\
\hline$\stackrel{\varrho}{\Xi}$ & 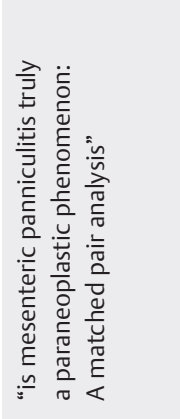 & 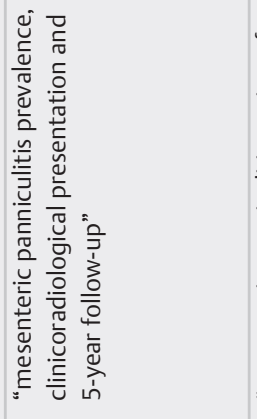 & 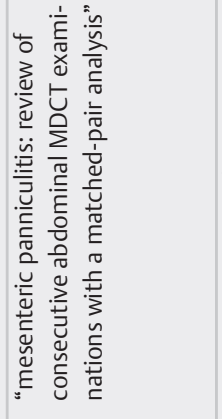 & 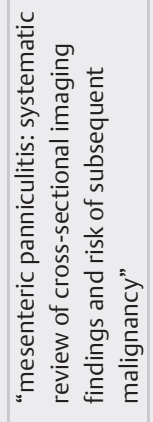 & 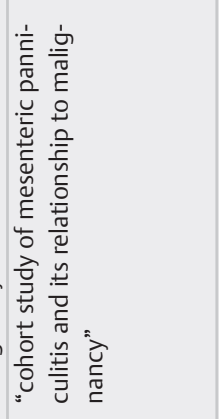 & 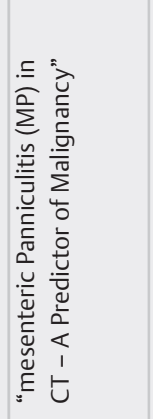 & 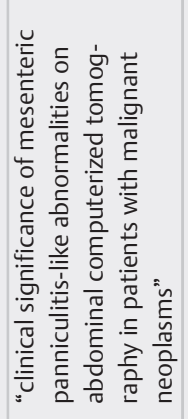 & 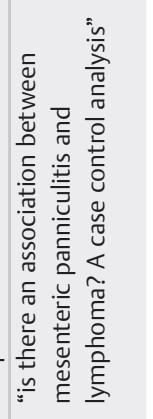 \\
\hline 高 & 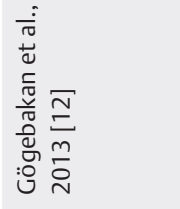 & 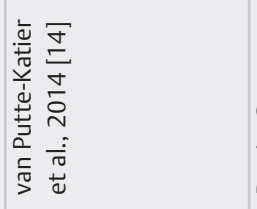 & 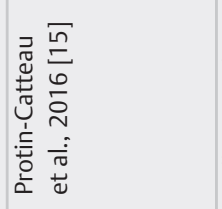 & 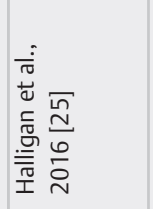 & 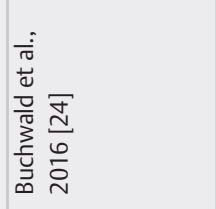 & 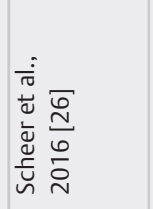 & 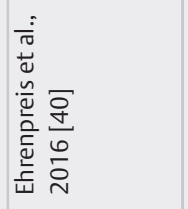 & 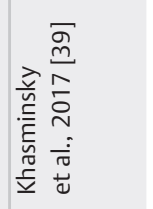 \\
\hline
\end{tabular}



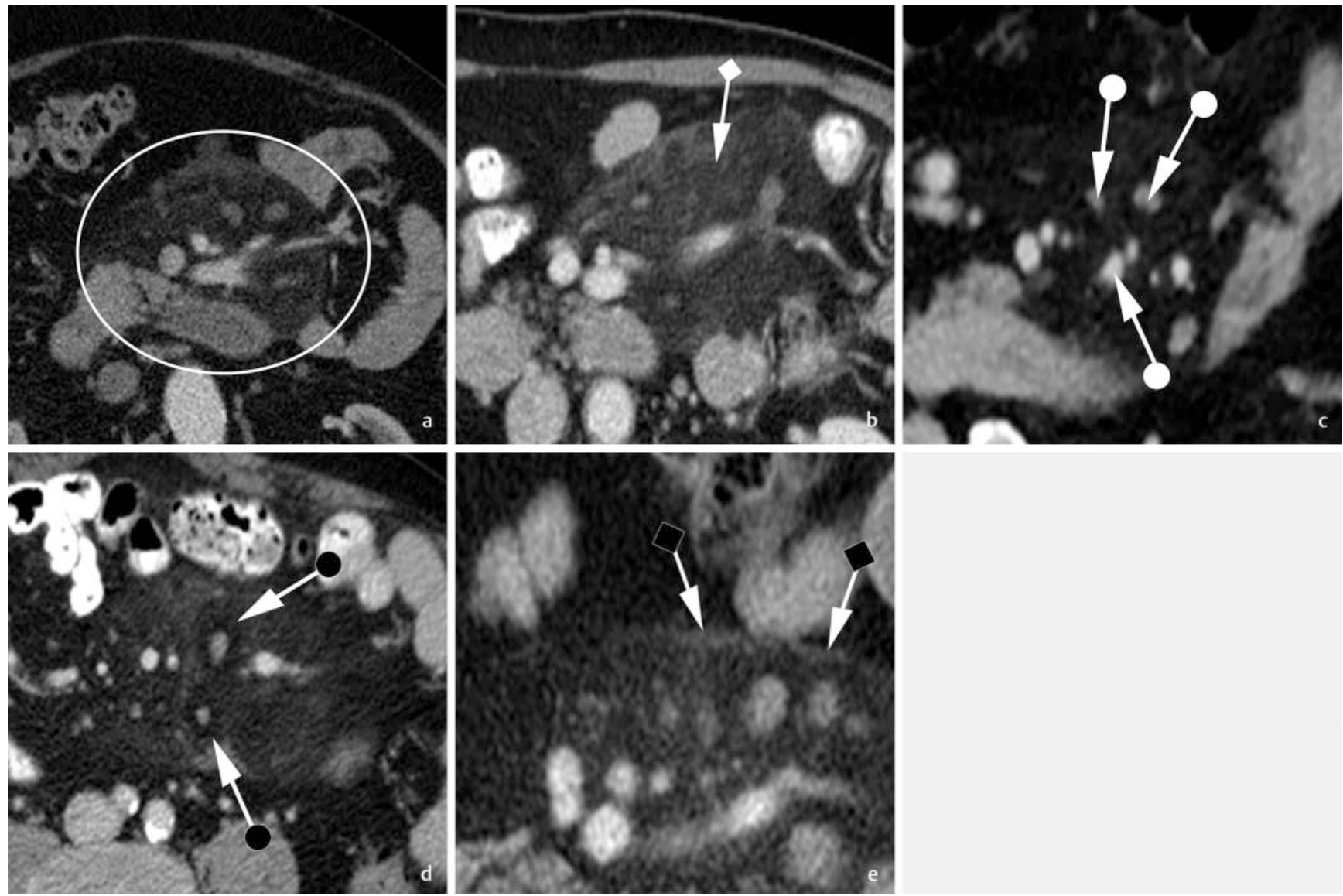

- Fig. 1 Enlarged view of CT image showing the 5 signs of mesenteric panniculitis (MP) according to Coulier [16]: a sign 1 - a well-defined fatty mass at the root of the small bowel mesentery displacing neighboring structures (ring), b sign 2 - like sign 1 with a higher attenuation than that of retroperitoneal or subcutaneous fat tissue (filled diamond), $\mathbf{c}$ sign 3 - lymph nodes within this well-defined fatty mass (filled circle), $\mathbf{d}$ sign $4-$ a hypodense halo surrounding blood vessels and nodes (open circle), e sign 5 - a hyperdense pseudocapsule surrounding the mesenteric fat with the lymph nodes within (open diamond).

- Abb. 1 Vergrößerte Darstellung der 5 CT-Zeichen einer Panniculitis mesenterialis (PM) nach Coulier [16]: a Zeichen 1 - Scharf abgrenzbare Fettmasse in der Mesenterialwurzel mit Verdrängung benachbarter Strukturen (Ring), b Zeichen 2 - Dichteanhebung/Imbibierung der unter a) beschriebenen Fettmasse verglichen mit dem retroperitonealen oder subkutanen Fettgewebe (gefüllte Quadrate), c Zeichen 3 - Mehrere Lymphknoten (gefüllte Kreise), d Zeichen 4 - Hypodenses Halo, welches Blutgefäße und Lymphknoten umgibt (offene Kreise), e Zeichen 5 - Hyperdense Pseudokapsel, welche die mesenteriale Fettmasse mit Lymphknoten allseits umgibt (offene Quadrate).

are absent, non-specific and/or atypical $[11,44]$, arguably indistinguishable from symptoms of concomitant disease.

Abnormal laboratory findings are usually absent or nonspecific. Some previous studies suggested an association with elevated CRP plasma levels or decreased hemoglobin [11, 13], but this was not confirmed by a recent case-control study [12].

\section{Imaging/diagnosis of MP}

MP is most commonly diagnosed incidentally by CT carried out for other reasons. According to the accepted definition by Coulier [16], CT diagnosis of MP requires the presence of at least 3 out of 5 typical signs listed in $>$ Table 1 and depicted in $>$ Fig. 1. For diagnosis of MP, it is obligatory that there is no infiltration of neighboring structures. In a few cases calcifications of the mesenteric mass were reported [41]. Four possible grades are assigned to each sign of MP and the grades of all signs are summarized, finally leading to one of the three grades of severity of MP listed in $>$ Table 2. Fig. 2 shows axial and coronal CTs of mild, moderate and marked MP appearance.

The most important differential diagnosis of MP is malignant lymphoma. Other differential diagnoses are inflammatory pseudotumor, dermoid tumor or pancreatitis.

MP may also be detected by MRI or ultrasound [19, 47]. PET-CT may be an option to distinguish between MP and lymphoma. Zissin et al. and Coulier et al. report on measurement of ${ }^{18} \mathrm{~F}-\mathrm{FDG}$ uptake as a marker for malignant lymphoma within surrounding MP, with even small lymphoma nodules displaying ${ }^{18} \mathrm{~F}-\mathrm{FDG}$ uptake $[8,48]$. Weiss et al. report on ${ }^{18}$ F-FDG uptake to distinguish between lymphoma and subcutaneous panniculitis [49]. However, PET-CT may not be sufficient to detect all malignant lymphoma so that biopsy remains advisable to safely rule out malignancy in equivocal cases [50]. CT, however, remains the diagnostic method of choice. 

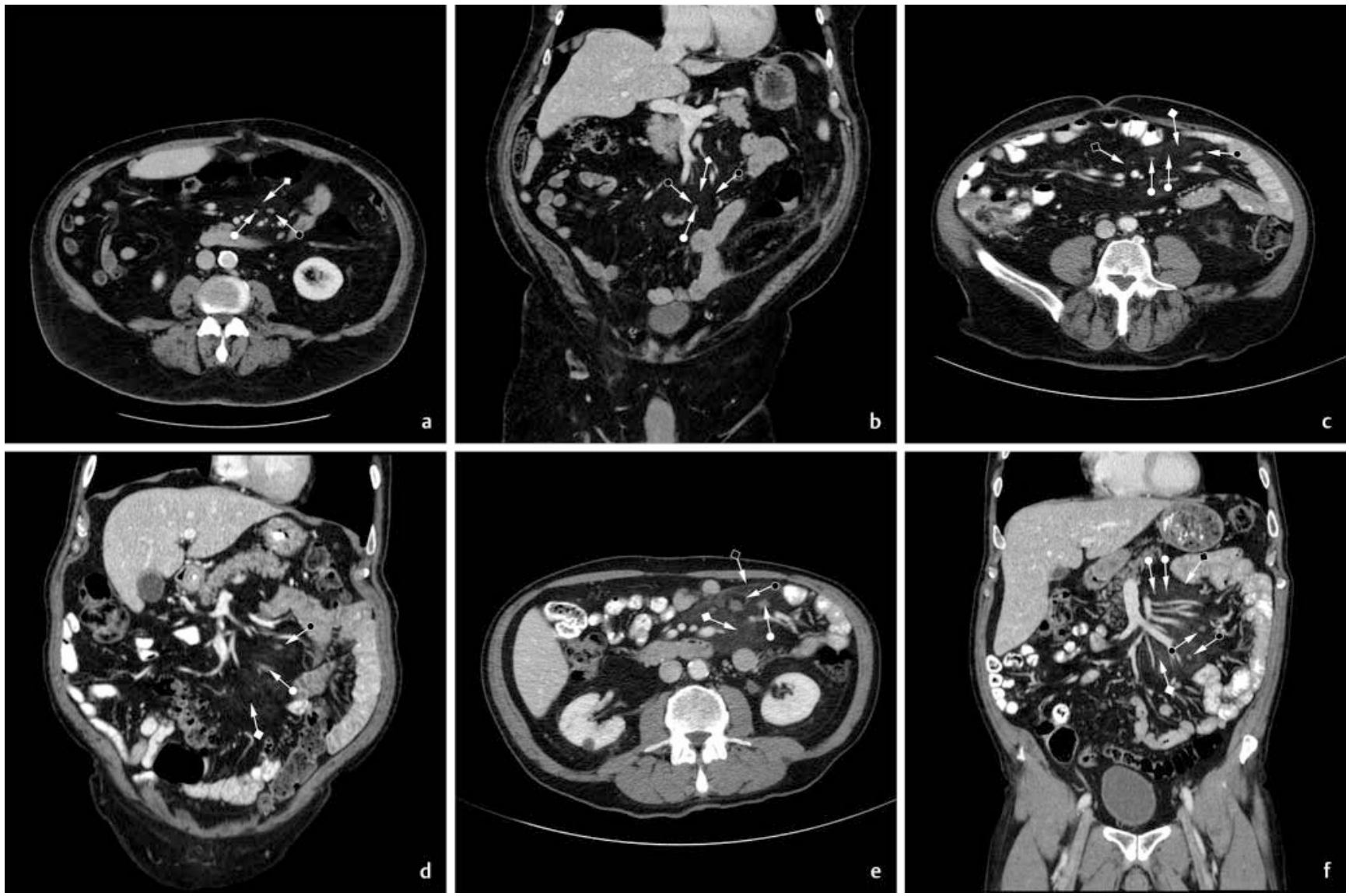

- Fig. 2 CT image of mesenteric panniculitis (MP) in axial a, $\mathbf{c}, \mathbf{e}$ and coronal $\mathbf{b}, \mathbf{d}, \mathbf{f}$ reformations, depicting three different grades of MP manifestations. According to Coulier [16] grades are 'mild', 'moderate', and 'marked'. a, b show mild MP (scores 0 - 4), c, $\mathbf{d}$ show moderate MP (scores 5-9), and e, f show marked MP (scores 10 - 15). Arrows depict four possible CT characteristics from which at least three have to be present for valid diagnosis of MP, these being mass lesion (filled circles), inhomogeneity (filled diamonds), hypodense fatty halo surrounding blood vessels and nodes (open circles) and hyperdense pseudocapsules (open diamonds); infiltration of neighboring structures excludes diagnosis of MP.

- Abb. 2 CT Bildgebung einer Panniculitis mesenterialis (PM) in axialer a, c, e und koronarer b, d, f Form, welche drei verschiedene Schweregrade der PM darstellt. Nach der Klassifizierung von Coulier [16] sind diese ,mild', ,moderat' und ,deutlich'. a, b zeigen eine milde PM (0 - 4 Punkte), c, d eine moderate PM (5 - 9 Punkte) und e, f eine starke PM (10 - 15 Punkte). Die Pfeile weisen auf vier der möglichen CT Charakteristika, wovon mindestens drei für eine sichere Diagnose der PM erfüllt sein müssen. Diese Charakteristika sind ,Raumforderung' (gefüllte Kreise), Inhomogenität (gefüllte Quadrate), eine hypodense Halo, welche Blutgefäße oder Knoten umgibt (offene Kreise), und eine hyperdense Pseudokapsel (offene Quadrate). Eine Infiltration der benachbarten Strukturen durch die Formation schließt das Vorliegen einer PM aus.

\section{Therapy}

Since MP is typically diagnosed as an incidental finding and most patients are asymptomatic, no treatment is warranted in the vast majority of patients [51]. In symptomatic cases, a number of drugs such as progesterone, corticosteroids, azathioprine, and a combination of corticosteroids with colchicine have been tried for treatment of this condition with results reported in small case series [52 - 54]. Corticosteroids in combination with tamoxifen constitute the preferred first-line therapy. Akram et al. reported on 20 patients treated with prednisolone and tamoxifen with follow-up by assessment of clinical symptoms and abdominal CT studies [18]. Before treatment, CT showed a single soft-tissue mass in the mesenteric root, with calcification in $61 \%$ of cases. In $34 \%$ of cases subtly increased density of the mesenteric fat with or without discrete soft tissue masses, small retroperitoneal and/ or mesenteric lymph nodes, and encasement of mesenteric ves- sels were found. In the remaining $5 \%$ of cases, no abdominal CT was available. After treatment, 12 patients (60\%) responded within 12 - 16 weeks, whereas 6 (30\%) showed persistent symptoms and 2 (10\%) even progressed. Unfortunately, the authors do not specify the particular changes of MP markers on posttreatment CT [18]. Other medications that have been used with some success include azathioprine, cyclophosphamide, progesterone and thalidomide $[51,53,54]$. Some case reports indicate rare cases where surgery was necessary for symptomatic relief, but in one such publication the CT image of supposed MP did not show the characteristic signs of MP, and pathology and CT findings suggested sclerosing mesenteritis [55]. Thus, case reports should be evaluated carefully with regard to the question of whether all described cases were indeed patients with MP. 


\section{Concluding remarks}

Mesenteric panniculitis (MP) is a nonspecific inflammatory condition of the mesenteric adipose tissue of unknown etiology. It is a relatively common coincidental finding on abdominal imaging with the vast majority of affected patients being asymptomatic.

Several studies have suggested an association of MP with neoplastic and other diseases. In particular, there has been much suspicion that MP may be associated with lymphoma, though the reported prevalence strongly varies $(7.8$ - $33 \%)[6,11,12,14-$ $17,24,26,40,48,50,56]$. However, recent studies with control groups showed no convincing statistical evidence of an association of MP with concomitant diseases including malignancies $[12,14,15,24-26,39]$. There is evidence from a single study that prostate carcinoma may be more common in patients with MP [14]. The greatest risk to the patient may be that benign MP is confused with a neoplastic disease such as lymphoma. Differentiation between malignant lymphoma and enlarged benign nodules in the context of MP is often difficult and may lead to spurious diagnosis of MP in the presence of lymphoma. There are, however, some reliable typical CT signs of MP such as "fat-ring" signs around nodules and vessels, a pseudocapsule surrounding the mesenteric mass, and the fact that MP has never been shown to infiltrate other organs or neighboring structures, unlike other mesenteric diseases such as lipoma, liposarcoma, lymphoma, and mesenteric carcinoma [8, 11, 38]. Conversely, nodules larger than $10 \mathrm{~mm}$ in the short axis diameter are suspicious of being lymphoma-related [11, 13, 19, 47]. Moreover, in contrast to MP, malignant lymphoma often presents with enlarged retroperitoneal or paraaortic lymph nodes.

PET-CT can be helpful in differentiating simple MP from MP co-existing with neoplasia such as lymphoma [57]. The specificity of PET-CT is very high, while the sensitivity is not $[8,40,57]$. Therefore, in a context of neoplasia, biopsy remains advisable in equivocal cases [50].

The scoring system for MP by Coulier et al. [16] is accepted in workgroups carrying out research studies on MP, since the scoring helps to standardize the signs of MP and its grading and makes it possible to compare results across different studies. Nevertheless, this scoring system is mainly relevant for academic purposes and has not become part of the daily clinical routine. The reason might be that the scoring system is not correlated with clinical symptoms and does not allow inference on any clinical relevance for the patient, future complications or a need of therapy.

From the recent studies, no convincing statistical evidence of an association of MP with concomitant diseases including malignancies can be inferred and therapy is usually not necessary in case of mesenteric panniculitis. Therefore, after diagnosis of MP, follow-up imaging is not indicated when lymphoma is reliably ruled out.

\section{Conflict of Interest}

The authors declare that they have no conflict of interest.
Literatur

[1] Jura V. Sulla mesenterite retrattile e sclerosante. Policlinico 1924; 31 : 575

[2] Perez-Fontan FJ, Soler R, Sanchez ] et al. Retractile mesenteritis involving the colon: barium enema, sonographic, and CT findings. American journal of roentgenology 1986; 147: 937 - 940

[3] Sabate JM, Torrubia S, Maideu J et al. Sclerosing mesenteritis: imaging findings in 17 patients. American journal of roentgenology 1999; 172: $625-629$

[4] Horton KM, Lawler LP, Fishman EK. CT findings in sclerosing mesenteritis (panniculitis): spectrum of disease. Radiographics 2003; 23: 1561-1567

[5] Emory TS, Monihan JM, Carr NJ et al. Sclerosing mesenteritis, mesenteric panniculitis and mesenteric lipodystrophy: a single entity? The American journal of surgical pathology 1997; 21: $392-398$

[6] Kipfer RE, Moertel CG, Dahlin DC. Mesenteric lipodystrophy. Annals of internal medicine 1974; 80: 582-588

[7] Mindelzun RE, Jeffrey RB Jr, Lane MJ et al. The misty mesentery on CT: differential diagnosis. American journal of roentgenology 1996; 167 : $61-65$

[8] Coulier B. Mesenteric panniculitis. Part 1: MDCT-pictorial review. JBRBTR: organe de la Societe royale belge de radiologie 2011; 94: 229-240

[9] Nyberg L, Bjork J, Bjorkdahl P et al. Sclerosing mesenteritis and mesenteric panniculitis - clinical experience and radiological features. BMC gastroenterology 2017; 17: 75

[10] Kuhrmeier A. Mesenteric lipodystrophy. Schweiz Med Wochenschr 1985; 115: $1218-1224$

[11] Daskalogiannaki M, Voloudaki A, Prassopoulos P et al. CT evaluation of mesenteric panniculitis: prevalence and associated diseases. American journal of roentgenology 2000; 174: 427 - 431

[12] Gogebakan O, Albrecht T, Osterhoff MA et al. Is mesenteric panniculitis truely a paraneoplastic phenomenon? A matched pair analysis. European journal of radiology 2013; 82: $1853-1859$

[13] Canyigit M, Koksal A, Akgoz A et al. Multidetector-row computed tomography findings of sclerosing mesenteritis with associated diseases and its prevalence. Japanese journal of radiology 2011; 29: 495 - 502

[14] van Putte-Katier N, van Bommel EF, Elgersma OE et al. Mesenteric panniculitis: prevalence, clinicoradiological presentation and 5-year followup. The British journal of radiology 2014; 87: 20140451

[15] Protin-Catteau L, Thiefin G, Barbe C et al. Mesenteric panniculitis: review of consecutive abdominal MDCT examinations with a matched-pair analysis. Acta radiologica 2016. doi:10.1177/0284185116629829

[16] Coulier B. Mesenteric panniculitis. Part 2: prevalence and natural course: MDCT prospective study. JBR-BTR: organe de la Societe royale belge de radiologie 2011; 94: $241-246$

[17] Wilkes A, Griffin N, Dixon L et al. Mesenteric panniculitis: a paraneoplastic phenomenon? Diseases of the colon and rectum 2012; 55: 806-809

[18] Akram S, Pardi DS, Schaffner JA et al. Sclerosing mesenteritis: clinical features, treatment, and outcome in ninety-two patients. Clin Gastroenterol Hepatol 2007; 5: 589 - 596; quiz 523-584

[19] Roson N, Garriga V, Cuadrado M et al. Sonographic findings of mesenteric panniculitis: correlation with CT and literature review. Journal of clinical ultrasound: JCU 2006; 34: 169-176

[20] Vlachos K, Archontovasilis F, Falidas E et al. Sclerosing Mesenteritis: Diverse clinical presentations and dissimilar treatment options. A case series and review of the literature. International archives of medicine 2011; 4: 17

[21] French WE, Bale GF, Winborn WB. Lipodystrophy of mesenteric fat. Surgery, gynecology \& obstetrics 1966; 122: 1046-1052

[22] Durst AL, Freund H, Rosenmann E et al. Mesenteric panniculitis: review of the leterature and presentation of cases. Surgery 1977; 81: $203-211$ 
[23] Cross A], McCormick J], Griffin N et al. Malignancy and mesenteric panniculitis. Colorectal disease: the official journal of the Association of Coloproctology of Great Britain and Ireland 2015. doi:10.1111/codi.13154

[24] Buchwald P, Diesing L, Dixon L et al. Cohort study of mesenteric panniculitis and its relationship to malignancy. Br J Surg 2016. doi:10.1002/ bjs. 10229

[25] Halligan S, Plumb A, Taylor S. Mesenteric panniculitis: systematic review of cross-sectional imaging findings and risk of subsequent malignancy. Eur Radiol 2016. doi:10.1007/s00330-016-4298-2

[26] Scheer F, Spunar P, Wiggermann P et al. Mesenteric Panniculitis (MP) in CT - A Predictor of Malignancy? Rofo 2016. doi:10.1055/s-0042110100

[27] Minato H, Shimizu J, Arano Y et al. IgG4-related sclerosing mesenteritis: a rare mesenteric disease of unknown etiology. Pathology international 2012; 62: $281-286$

[28] Nomura Y, Naito Y, Eriguchi N et al. A case of IgG4-related sclerosing mesenteritis. Pathology, research and practice 2011; 207: 518-521

[29] Schaffler A, Scholmerich J, Buchler C. Mechanisms of disease: adipocytokines and visceral adipose tissue-emerging role in intestinal and mesenteric diseases. Nat Clin Pract Gastroenterol Hepatol 2005; 2: 103 111

[30] Bush RW, Hammar SP Jr, Rudolph RH. Sclerosing mesenteritis. Response to cyclophosphamide. Archives of internal medicine 1986; 146: 503 505

[31] Hartz R, Stryker S, Sparberg M et al. Mesenteric tumefactions. The American surgeon 1980; 46: 525- 529

[32] Rao PM, Austin RF. Mesenteric Panniculitis Presenting as an Acute Abdomen. Emergency Radiology 1996; 3: 43-45

[33] Signorelli SS, Fiore V, Mangiafico $M$ et al. The chance case history of an unusual disease: mesenteric panniculitis. Internal and emergency medicine 2015; 10: $883-884$

[34] Goh J, Otridge B, Brady H et al. Aggressive multiple myeloma presenting as mesenteric panniculitis. The American journal of gastroenterology 2001; 96: $238-241$

[35] Ogden WW 2nd, Bradburn DM, Rives JD. Mesenteric Panniculitis: Review of 27 Cases. Annals of surgery 1965; 161: 864-875

[36] Badiola-Varela CM, Sussman SK, Glickstein MF. Mesenteric panniculitis: findings on CT, MRI, and angiography. Case report. Clinical imaging 1991; 15: $265-267$

[37] Ege G, Akman H, Cakiroglu G. Mesenteric panniculitis associated with abdominal tuberculous lymphadenitis: a case report and review of the literature. The British journal of radiology 2002; 75: 378-380

[38] Friedman AC, Hartman DS, Sherman J et al. Computed tomography of abdominal fatty masses. Radiology 1981; 139: 415-429

[39] Khasminsky V, Ram E, Atar E et al. Is there an association between mesenteric panniculitis and lymphoma? A case control analysis. Clin Radiol 2017. doi:10.1016/j.crad.2017.05.008
[40] Ehrenpreis ED, Roginsky G, Gore RM. Clinical significance of mesenteric panniculitis-like abnormalities on abdominal computerized tomography in patients with malignant neoplasms. World journal of gastroenterology 2016; 22: $10601-10608$

[41] Gundara JS, Ip JC, Glover AR et al. Sclerosing mesenteritis: a diagnosis worth considering. ANZ journal of surgery 2013; 85: 291 - 292

[42] Newman PA, Thahal H, Chaudhery B. Mesenteric panniculitis. BM] case reports 2014: 1 - 2. doi:10.1136/bcr-2014-203911

[43] Schattner A, Feldberg E, Adi M. Unremitting abdominal pain: obscure until the first CT. Postgraduate medical journal 2014; 90: 298-299

[44] Amor F, Farsad M, Polato R et al. Mesenteric panniculitis presenting with acute non-occlusive colonic ischemia. International archives of medicine 2011; 4: 22

[45] Kida T, Suzuki K, Matsuyama T et al. Sclerosing mesenteritis presenting as protein-losing enteropathy: a fatal case. Intern Med 2011; 50: 2845 2849

[46] Patel N, Saleeb SF, Teplick SK. Cases of the day - General Case of the Day. RadioGraphics 1999; 19: 1083-1085

[47] van Breda Vriesman AC, Schuttevaer HM, Coerkamp EG et al. Mesenteric panniculitis: US and CT features. Eur Radiol 2004; 14: $2242-2248$

[48] Zissin R, Metser U, Hain D et al. Mesenteric panniculitis in oncologic patients: PET-CT findings. The British journal of radiology 2006; 79: $37-43$

[49] Weiss ], Horger M, Muller M et al. Imaging of panniculitis-like subcutaneous T-cell lymphoma. Rofo 2015; 187: 511 - 515

[50] Ehrenpreis ED, Rao AS, Aki R et al. Normal Positron Emission Tomography-Computerized Tomogram in a Patient with Apparent Mesenteric Panniculitis: Biopsy Is Still the Answer. Case reports in gastroenterology 2009; 3: 131 - 137

[51] Hillemand CGP, Clarke R, Murphy S]. Abdominal Pain from Sclerosing Mesenteritis. Clin Gastroenterol Hepatol 2011; 9: A22

[52] Bala A, Coderre SP, Johnson DR et al. Treatment of sclerosing mesenteritis with corticosteroids and azathioprine. Canadian journal of gastroenterology = Journal canadien de gastroenterologie 2001; 15: 533 - 535

[53] Genereau T, Bellin MF, Wechsler B et al. Demonstration of efficacy of combining corticosteroids and colchicine in two patients with idiopathic sclerosing mesenteritis. Digestive diseases and sciences 1996; 41: 684 688

[54] Mazure R, Fernandez Marty P, Niveloni S et al. Successful treatment of retractile mesenteritis with oral progesterone. Gastroenterology 1998; 114: $1313-1317$

[55] Fujikawa T, Yasuhara H, Matsumi A et al. A case of mesenteric panniculitis requiring an operation. BMJ case reports 2014: 1 -2. doi:10.1136/ bcr-2014-205028

[56] Ogden WW 2nd, Bradburn DM, Rives JD. Pannicultis of the mesentery. Annals of surgery 1960; 151: 659-668

[57] Zissin R, Metser U, Lerman H et al. PET-CT findings in surgically transposed ovaries. The British journal of radiology 2006; 79: 110-115 